\begin{tabular}{c|c}
\hline International Journal of Current Research in \\
Biosciences and Plant Biology \\
\hline EXCELLENT \\
PUBLISHERS
\end{tabular}

Review Article

doi: http://dx.doi.org/10.20546/ijcrbp.2017.402.001

\title{
Vitamin D Assay in Human Serum Samples: A Review of Analysis Methods
}

\author{
Wei Zhang ${ }^{1 \#}$, Jun Wang ${ }^{1}{ }^{* \#}$, Rui Cao ${ }^{2}$, Hong C. Lai ${ }^{3}$, Zhiyuan Mi ${ }^{1}$, Jiangtao Su$^{1}$, Jingyu Xiao ${ }^{4}$ and \\ Miaozi Gong ${ }^{5} *$
}

\author{
${ }^{1}$ Bioengineering and Food College, Hubei University of Technology, Wuhan, Hubei 430068, China \\ ${ }^{2}$ Department of Chemistry, Johns Hopkins University, Baltimore, MD 21218, USA \\ ${ }^{3}$ Department of Radiology, Johns Hopkins School of Medicine, Baltimore, MD 21205, USA \\ ${ }^{4}$ Hubei Wuchang Experimental Middle School, Wuhan, Hubei 430061, China \\ ${ }^{5}$ Department of Pathology, Peking University Shougang Hospital, Beijing 100144, China
}

*Corresponding authors; ${ }^{\#}$ These two authors contributed equally to this paper.

\begin{tabular}{|c|c|}
\hline Abstract & Article Info \\
\hline \multirow{7}{*}{$\begin{array}{l}\text { Vitamin D was discovered about one century ago, which is part of the family of } \\
\text { hormones. Vitamin D supplements have been commonly used in medical prescription. } \\
\text { Deficiency of Vitamin } \mathrm{D}_{3} \text { has been related to various severe diseases, including } \\
\text { cardiovascular disease, cancer and diabetes. Therefore, fast and reliable analytic methods } \\
\text { for Vitamin D are very important for clinical diagnosis and treatment, as well as for } \\
\text { biomedical research. To date, immunoassay, LC-MS/MS and HPLC are three major } \\
\text { methods for the qualification and quantitation of Vitamin D. In this paper, we will go } \\
\text { through the advantage, disadvantage and limits of each method and provide advice for } \\
\text { future analysis of this group of hormone. }\end{array}$} & $\begin{array}{l}\text { Accepted: } 14 \text { January } 2017 \\
\text { Available Online: 06 February } 2017\end{array}$ \\
\hline & Keywords \\
\hline & HPLC \\
\hline & Immunoassay \\
\hline & LC-MS/MS \\
\hline & Vitamin D \\
\hline & Vitamin D assays \\
\hline
\end{tabular}

\section{Introduction}

Vitamin D was discovered in cod liver oil by McCollum et al. in 1922. The active substance in cod liver for the treatment of rickets was found to be Vitamin $\mathrm{D}$, which was a break-through discovery in the history of medicine (DeLuca, 2004). Modern research studies have shown that Vitamin D can be produced in skin by irradiation of sunlight (Chick and Roscoe, 1926). The photolytic synthesis produces Vitamin $\mathrm{D}_{3}$ from a derivative of cholesterol (DeLuca, 2004). Vitamin $D_{2}$ can be produced by irradiation of ergosterol (DeLuca, 2004). Unlike other vitamins, Vitamin $\mathrm{D}$ is part of the family of hormones.
Generally, it is not present in common foods, either vegetation or meat with exceptions of some very uncommon food such as fish liver oils (Ross et al., 2011).

The structure of Vitamin $\mathrm{D}_{2}$ was determined by Askew et al. in 1931, while the structure of Vitamin $\mathrm{D}_{3}$ was unveiled by Windaus et al. in 1936. The structure of the Vitamin D family is shown in Fig. 1 (Wang et al., 2016; Wolf, 2004). Vitamin D is converted in the human body to an active form and circulated as 25-hydroxyvitamin D [25(OH)D]. The metabolism is shown in Fig. 2 (DeLuca, 2004). In the application of current clinical practices, the level of 
$25(\mathrm{OH}) \mathrm{D}$ in serum is monitored. There are three goals to achieve by measuring $25(\mathrm{OH}) \mathrm{D}$ in clinical practices (Holick et al., 2011). The first is to diagnose Vitamin D insufficiency or deficiency in patients (Holick, 2007). Secondly, it is important to monitor the response to Vitamin D supplements (Zeghoud et al., 1997). Thirdly, it is also necessary to diagnose Vitamin D toxicity in some rare cases (Pettifor et al., 1995).

The physiological role of Vitamin D is closely linked to the mineralization of bone, the regulation of calcium ion and phosphate concentration in the bone and plasma, and a number of cancer prevention mechanisms (Fig. 3) (Wan et al., 2016).
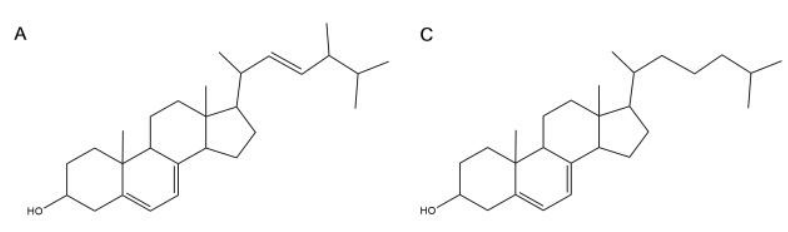

B
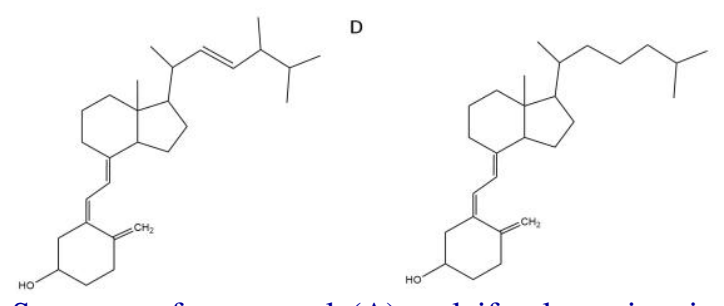

Fig. 1: Structure of ergosterol (A), calciferol or vitamin $D_{2}$ (B), 7-dehydrocholesterol (C), and cholecalciferol or vitamin $\mathrm{D}_{3}$ (D).
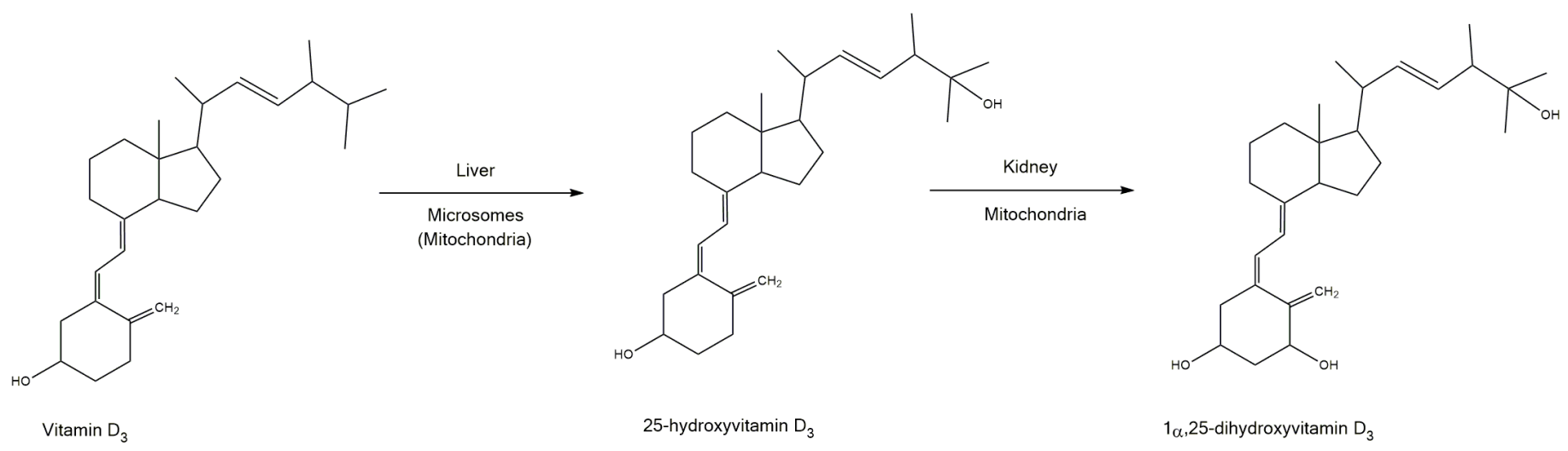

Fig. 2: Vitamin $\mathrm{D}_{3}$ conversion to 25-hydroxyvitamin $\mathrm{D}$ in the liver mitochondria by vitamin $\mathrm{D}$ 25-hydroxylase. In the kidney, 25hydroxyvitamin D is further hydroxylated to form the 1,25-dihydroxyvitamin D by 1-alpha-hydroxylase (DeLuca, 2004).

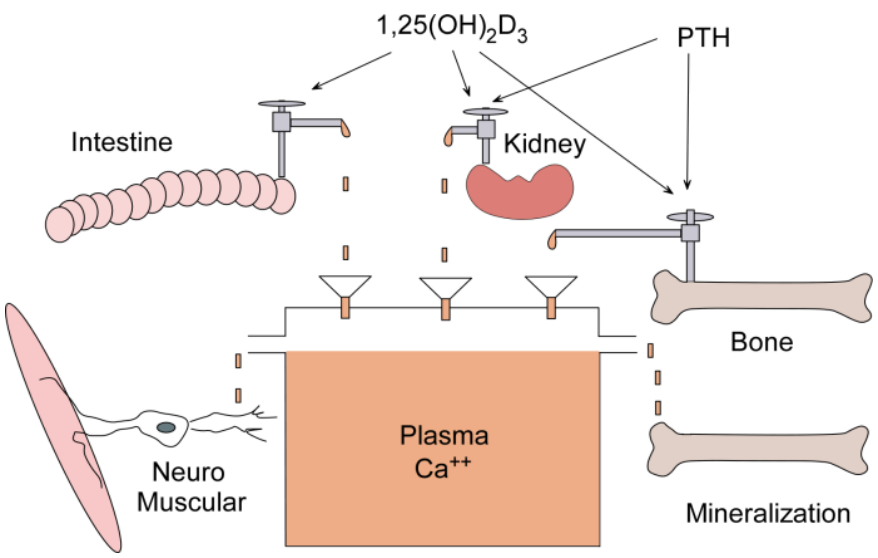

Fig. 3: Diagrammatic representation of the role of the vitamin $\mathrm{D}$ hormone and the parathyroid hormone (PTH) in increasing plasma calcium concentrations to prevent hypocalcemic tetany (neuromuscular) and to provide for mineralization of the skeleton.

The common test methods for the determination of Vitamin D level in serum can be divided into three categories: immunoassay, LC-MS/MS, and HPLC. Immunoassay is widely accepted as a standard monitoring method used for most patients due to its simplicity and inexpensive operation. Immunoassay will generate accurate quantitative results of the total $25(\mathrm{OH}) \mathrm{D}$ level in serum samples.

LC-MS/MS is used in some special cases. It can be used to differentiate the two forms of Vitamin $\mathrm{D}$ in serum, which are $25(\mathrm{OH}) \mathrm{D}_{2}$ and $25(\mathrm{OH}) \mathrm{D}_{3}$. In infant patients, the amount of the C-3 epimer of $25(\mathrm{OH}) \mathrm{D}_{3}$ is high in blood and it can be separated by LC-MS/MS to remove interference of the Vitamin D levels. Also, LC-MS/MS can be used to quantify the $1,25(\mathrm{OH}) \mathrm{D}$ level, which is used to assess the condition of patients on Vitamin D therapy with chronic kidney disease.

HPLC separation and quantitation of Vitamin D has been developed with UV detection. Three types of separation including normal phase, reversed phase, and a 
combination of the two have been reported. The sample preparation and the interpretation of the chromatogram was complicated, which limited the use of HPLC methods in routine clinical works. However, some of the HPLC methods achieved great sensitivity and selectivity over other methods.

In this review, the three categories of Vitamin D analysis will be covered in detail with examples in the literature. The advantages and disadvantages of each will be carefully compared and discussed. The trend of current works and the guidance for future research will also be provided.

\section{Immunoassay}

Immunoassay, especially radioimmunoassay, was developed by Rosalyn Sussman Yalow, an American female medical physicist who won the 1977 Nobel Prize in Physiology or Medicine (Yalow, 1983; Glick, 2011). It has been a revolutionary technique in clinical testing of almost every field of medicine, opening doors to the measurement of hormone, vitamins, drug substances, biomarkers, and other macro-molecules.

The first work of clinically used immunoassay on the analysis of Vitamin D in blood samples was published in 1971 by Haddad and Chyu. The use of a simple procedure of competitive radioimmunoassay eliminated the lengthy and tedious preparation in the chemical separation and bioassay methods. In the commonly used competitive ligand radioimmunoassay, a certain amount of radioactive isotope marked $25(\mathrm{OH}) \mathrm{D}$ was added together with the unmarked sample, into a binding protein. If there is no $25(\mathrm{OH}) \mathrm{D}$ in the sample, the bonded form will only be the radio-marked ones.
The existence of $25(\mathrm{OH}) \mathrm{D}$ in the sample will compete with the marked and inhibit the binding of the radiomarked molecules. Thus, a detection of radioactive level of the resulting bonded material enables the calculation of the level of the $25(\mathrm{OH}) \mathrm{D}$ in the sample.

With the fast-growing demand for Vitamin D test worldwide, numerous commercially available test kits have been developed and adopted as a routine clinical standard, such as the products from Abbott (Architect), DiaSorin (LIAISON), IDS (ISYS), Roche (E170), and Siemens (Centaur). The Food and Drug Administration (FDA) has approved the radioiodine based method for clinical use. Many of them have achieved automated analysis to increase the output, reduce the work load, and eliminate possible human error. The operation of the radioimmunoassay needs minimal amount of training, and the test kits are available at relatively low prices. In addition, the processing time is fast. All those factors lead to a tremendous popularity. However, the reliability of the methods has been questioned.

Characteristics for some commercial Vitamin D assays are listed in Table 1. As a leading provider of commercial assays, DiaSorin claimed a wide linear range of $4-150 \mathrm{ng} / \mathrm{mL}, 100 \%$ recovery of $25(\mathrm{OH}) \mathrm{D}$, and a good inter-assay precision of $\pm 11.7 \%$. However, a lower recovery of $82 \%$ was reported by Carter et al. (2007); Hollis (2000) also pointed out that many of the commercial assays including the products from DiaSorin and Immuno-Diagnostic Systems (IDS) were not standardized against reference material. In the range of 10-40 ng/mL, the immunoassay could have underestimated the level of total circulating $25(\mathrm{OH}) \mathrm{D}$ (Hollis, 2000).

Table 1. Characteristics for common commercial Vitamin D assays.

\begin{tabular}{lllll}
\hline Assay & Extraction & Range $(\mathbf{n g} / \mathbf{m L})$ & LOD $(\mathbf{n g} / \mathbf{m L})$ & Precision \\
\hline DiaSorin (2016) & Acetonitrile & $4-150$ & 4.0 & $11.7 \%$ \\
IDS (2015) & NaOH /Acetonitrile & $0-225$ & 3.0 & $5.3 \%$ \\
Abbott (2016) & Ethanol & $0-160$ & 3.1 & $3.7 \%$ \\
Roche (2012) & Buffer /Acetonitrile & $3-70$ & 3.0 & $11.5 \%$ \\
Siemens (Chen et al., 2012) & N/A & $4.2-150$ & 4.2 & $11.9 \%$ \\
\hline
\end{tabular}

In a study by Turpeinen et al. (2003) the test kits from DiaSorin and IDS was closely compared with a validated HPLC assay. The results showed in the range of the claimed concentrations, the coefficient of variation $(\mathrm{CV})$ are generally acceptable (between $4 \%$ and 17\%). However, the correlation between the HPLC and the DiaSorin or IDS methods are poor. This was also mentioned by Hollis et al. with a hypothesis of problems in the pre-treatment and/or extraction procedure (Hollis 2000). 


\section{LC-MS/MS}

LC-MS/MS has used as reference methods for the validation of the immunoassay methods mentioned above. The LC-MS/MS carries great identification and quantitation capabilities. It was considered to be the "golden standard" for the identification and quantitation of many analytes. However, the competitivity and higher knowledge requirements for the operators limited the use to the research purposes other than regular tests.

There are some LC-MS/MS methods developed for the quantitation of Vitamin D related metabolites. Most of the methods require the use of derivatization in the sample treatment. For example, in the study by Higashi and co-workers, the derivatization was performed using a Cookson-type reagent, which increased the complexity of the method (Higashi et al., 2000). In a published method by Saenger et al. (2006), deuterated $\Delta 9$-THC-D3 was added as internal standard. The three major compounds of $25(\mathrm{OH}) \mathrm{D}_{2}$, $25(\mathrm{OH}) \mathrm{D}_{3}$ and $\Delta^{9}-\mathrm{THC}-\mathrm{D}_{3}$ were successfully separated using a simple HPLC procedure with methanol and acetate buffers. The run time was 6 minutes and all three compounds of interest were eluted within 3 minutes. Then the analytes were ionized using electrospray ionizer. The transitions used when monitoring the multiple-reaction were $318.15>196.20$ for $\Delta^{9}-$ THC$-\mathrm{D}_{3}, 401.15>365.25$ for $25(\mathrm{OH}) \mathrm{D}_{3}$, and $413.15>355.20$ for $25(\mathrm{OH}) \mathrm{D}_{2}$. The quantification was achieved by calculating of the integrated peak area ratio between the two Vitamin D derivatives and the internal standard $\Delta^{9}-$ THC- $D_{3}$. The performance of this method was promising with a very low limit of detection at $0.09 \mathrm{ng} / \mathrm{mL}$, a linear rage of $0-200 \mathrm{ng} / \mathrm{mL}$ and an inter-assay $\mathrm{CV}$ of $11.5 \%$ (Saenger et al., 2006).

Another example of robust and reliable LC-MS/MS analysis of Vitamin D was reported by van den Ouweland et al. (2010). The performance of the developed LC-MS/MS method was compared to some popular commercial immunoassays including DiaSorin and Roche ECLIA. There are several LC-MS/MS methods published and the major difference is the procedure of calibration, which is also the major factor affecting the CV (Leino et al., 2008; Roth et al., 2008). In this study, the newly released reference standard material for 25-OH Vitamin D was used (SRM 972 and SRM 2972) (NIST, 2009 and 2014). The use of common standard was likely to reduce the interlaboratory $\mathrm{CV}$ for individual test methods.

In Ouweland's method, the sample was treated to remove the protein from the serum, followed by a solid-phase extraction. Strata C18-E SPE column was used and the recovery rate was calculated to be $85 \%$. Then a gradient HPLC was used to separate the analyte of interest. The retention times are $3.01 \mathrm{~min}$ for $25(\mathrm{OH}) \mathrm{D}_{3}$ and $3.06 \mathrm{~min}$ for $25(\mathrm{OH}) \mathrm{D}_{2}$, with acceptable separation. The fragments of $25(\mathrm{OH}) \mathrm{D}_{3}$ and $25(\mathrm{OH}) \mathrm{D}_{2}$ was detected by selected reaction monitoring using $\mathrm{m} / \mathrm{z}$ transitions of $401.5>159.2$ and 413.4>83.1, respectively.

Limit of detection of the above method was $0.8 \mathrm{ng} / \mathrm{mL}$ and the range was tested to be $0-220 \mathrm{ng} / \mathrm{mL}$, which provided a good coverage for common patients. When comparing with the immunoassay results, the DiaSorin kit showed a good correlation along the range. However, Roche ECLIA clearly overestimated the values of vitamin $\mathrm{D}$ in patients with higher level of vitamin D (above $20 \mathrm{ng} / \mathrm{mL}$ ).

Despite of the complexity and high cost of equipment and operation, LC-MS/MS continuously delivered reliable data of vitamin D in human samples. With the commercialization of common standards by NIST, the LC-MS/MS has become a reference method for the performance evaluation of other assays.

\section{HPLC}

As a common analyte, Vitamin D assays using HPLC have been investigated and reviewed thoroughly in the late 1990s and early 2000s. There are numerous HPLC methods developed to separate Vitamin forms of $25(\mathrm{OH}) \mathrm{D}, 1,25(\mathrm{OH}) \mathrm{D}_{2}$ and $24,25(\mathrm{OH}) \mathrm{D}_{2}$ as well as many metabolites.

The first measurements using HPLC can be dated back to the late 1970s. Eisman and co-workers achieved $72.2 \%$ recovery of ${ }^{3} \mathrm{H}-25(\mathrm{OH}) \mathrm{D}_{3}$ with UV detection at $254 \mathrm{~nm}$ (Eisman et al., 1976). Internal standards whether prepared in house or available from NIST were both widely used in the quantification.

\section{Conflict of interest statement}

Authors declare that they have no conflict of interest. 


\section{References}

Abbott, 2016. Technical Note of Architect 25-OH Vitamin D Assay, Abbott Laboratories.

Askew, F. A., Bourdillon, R. B., Bruce, H. M., Jenkins, R. G. C., Webster, T. A., 1930. The distillation of vitamin D. Proceedings of the Royal Society of London. Series B, Containing Papers of a Biological Character. 107(748), 76-90.

Carter, G. D., Jones, J. C., Berry, J. L., 2007. The anomalous behaviour of exogenous 25hydroxyvitamin D in competitive binding assays. J. Steroid Biochem. Mol. Biol. 103(3-5), 480-482.

Chen, Y., Kinney, L., Božović, A., Smith, H., Tarr, H., Diamandis, E. P., LeBlanc, A., 2012. Performance evaluation of Siemens ADVIA Centaur and Roche MODULAR Analytics E170 Total 25-OH Vitamin D assays. Clin. Biochem. 45(16-17), 1485-1490.

Chick, H., Roscoe, M. H., 1926. Influence of diet and sunlight upon the amount of vitamin A and vitamin D in the milk afforded by a cow. Biochem. J. 20(3), 632.

DeLuca, H. F., 2004. Overview of general physiologic features and functions of vitamin D. Am. J. Clin. Nutr. 80(6), 1689S-1696S.

DiaSorin, 2016. 25-hydroxyvitamin D: From bone and mineral to general health marker. DiaSorin Product Introduction.

Eisman, J. A., Hamstra, A. J., Kream, B. E., DeLuca, H. F., 1976. A sensitive, precise, and convenient method for determination of 1,25-dihydroxyvitamin $\mathrm{D}$ in human plasma. Arch. Biochem. Biophys. 176(1), 235-243.

Glick, S., 2011. Rosalyn Sussman Yalow (1921-2011). Nature. 474, 580.

Haddad, J. G., Chyu, K. J., 1971. Competitive proteinbinding radioassay for 25-hydroxycholecalciferol. J. Clin. Endocrinol. Metab. 33(6), 992-995.

Higashi, T., Awada, D., Shimada, K., 2001. Simultaneous determination of 25-hydroxyvitamin D2 and 25-hydroxyvitamin D3 in human plasma by liquid chromatography-tandem mass dpectrometry employing derivatization with a Cookson-type reagent. Biol. Pharmaceut. Bull. 24(7), 738-743.

Holick, M. F., 2007. Vitamin D deficiency. New Eng. J. Med. 357(3), 266-281.

Holick, M.F., Binkley, N.C., Bischoff-Ferrari, H.A., Gordon, C.M., Hanley, D.A., Heaney, R.P., Murad, M.H., Weaver, C.M., 2011. Evaluation, treatment, and prevention of vitamin D deficiency: An Endocrine Society clinical practice guideline. J.
Clin. Endocrinol. Metabol. 96(7), 1911-1930.

Hollis, B. W., 2000. Comparison of commercially available 125I-based RIA methods for the determination of circulating 25-hydroxyvitamin D. Clin. Chem. 46(10), 1657-1661.

IDS (Immunodiagnostic Systems), $2015 . \quad 1,25$ Dihydroxy Vitamin D EIA. IDS Product Introduction.

Leino, A., Turpeinen, U., Koskinen, P., 2008. Automated measurement of $25-\mathrm{OH}$ vitamin D on the Roche Modular E170 analyzer. Clin. Chem. 54, 2059-2062.

McCollum, E. V., Simmonds, N., Becker, E., 1922. Studies on experimental rickets. XXI. An experimental demonstration of the Existence. J. Biol. Chem. 53, 293-312.

NIST, 2009. Certificate of Analysis Standard Reference Material 972. National Institute of Standards and Technology, Certificate of Analysis.

NIST, 2014. Certificate of Analysis Standard Reference Material 2972. National Institute of Standards and Technology, Certificate of Analysis.

Pettifor, J. M., Bikle, D. D., Cavaleros, M., Zachen, D., Kamdar, M. C., Ross, F. P., 1995. Serum levels of free 1, 25-dihydroxyvitamin $\mathrm{D}$ in vitamin $\mathrm{D}$ toxicity. Ann. Internal Med. 122(7), 511-513.

Roche, 2012. Electro-chemiluminescence Binding Assay (ECLIA) for the In-Vitro Determination of Total 25-hydroxyvitamin D. Total Fact Sheet Elecsys ${ }^{\circledR}$ Vitamin D Total Assay.

Ross, A. C., Taylor, C. L., Yaktine, A. L., Del Valle, H. B., 2011. Dietary Reference Intakes for Calcium and Vitamin D. National Academies Press, Washington, DC.

Roth, H. J., Schmidt-Gayk, H., Weber, H., Niederau, C., 2008. Accuracy and clinical implications of seven 25-hydroxyvitamin D methods compared with liquid chromatography-tandem mass spectrometry as a reference. Ann. Clin. Biochem. 45(2), 153-159.

Saenger, A. K., Laha, T. J., Bremner, D. E., Sadrzadeh, S. M. H., 2006. Quantification of serum 25hydroxyvitamin and using HPLC-Tandem Mass Spectrometry and examination of reference intervals for diagnosis of vitamin D deficiency. Am. J. Clin. Pathol. 125(6), 914-920.

Turpeinen, U., Hohenthal, U., Stenman, U.-H., 2003. Determination of 25-hydroxyvitamin D in serum by HPLC and immunoassay. Clin. Chem. 49(9), 15211524.

van den Ouweland, J. M., Beijers, A. M., Demacker, P. N., van Daal, H., 2010. Measurement of 25-OH- 
vitamin $\mathrm{D}$ in human serum using liquid chromatography tandem-mass spectrometry with comparison to radioimmunoassay and automated immunoassay. J. Chromatogr. B Analyt. Technol. Biomed. Life Sci. 878(15-16), 1163-1168.

Wang, J., Cao, R., Zhang, W., Mi, Z., Su, J., You, X., Keceli, G., Wang, Y., Lai, H. C., 2016. Whether vitamin D can prevent cancer or not: Recent research progress in vitamin $\mathrm{D}$ and major cancers. Int. J. Curr. Res. Biosci. Plant Biol. 3(11), 108-114.

Windaus, A., Schenck, F., Werder, F. T., 1936. Über das antirachitisch wirksame Bestrahlungsprodukt ans 7-
Dehydro-cholesterin. In: Hoppe-Seyler's Zeitschrift für Physiologische Chemie, Vol. 241, 100p.

Wolf, G., 2004. The discovery of vitamin D: The contribution of Adolf Windaus. J. Nutr. 134(6), 1299-1302.

Yalow, R. S., 1983. Radioimmunoassay. Hutchinson Ross Publishing Company.

Zeghoud, F., Vervel, C., Guillozo, H., Walrant-Debray, O., Boutignon, H., Garabédian, M., 1997. Subclinical vitamin D deficiency in neonates: Definition and response to vitamin D supplements. Am. J. Clin. Nutr. 65(3), 771-778.

\section{How to cite this article:}

Zhang, W., Wang, J., Cao, R., Lai, H. C., Mi, Z., Su, J., Xiao, J., Gong, M., 2017. Vitamin D assay in human serum samples: A review of analysis methods. Int. J. Curr. Res. Biosci. Plant Biol. 4(2), 1-6.

doi: http://dx.doi.org/10.20546/ijcrbp.2017.402.001 